\section{Cognitive issues observed in the adoption of guidelines for earthquake- resistant masonry construction}

\author{
P. P. Sivan ${ }^{1,4, *}$, A. Praveen ${ }^{2}$ and C. Gajendran ${ }^{3}$ \\ ${ }^{1}$ Department of Civil Engineering, Government Engineering College, \\ Trichur 680 009, India \\ ${ }^{2}$ Department of Civil Engineering, Rajiv Gandhi Institute of \\ Technology, Kottayam 686 501, India \\ ${ }^{3}$ School of Civil Engineering, Karunya University, \\ Coimbatore 641 114, India \\ ${ }^{4}$ School of Civil Engineering, Karunya University, \\ Coimbatore 641 114, India
}

The cognitive appreciation of seismic risk among the local population is one of the key drivers in the adoption of guidelines issued for earthquake-resistant masonry construction. The present study gives a broader perspective on the cognitive vulnerability that exists among the local population in understanding and adopting the proposed earthquake-resistant construction guidelines based on a detailed evaluation of the prevailing practices at two regions in Kerala, India. The exercise was carried out among 197 houses located in the above regions, which included both recently built homes and those with exposure to earlier earthquakes. The study highlights the need for evolving technology-supported intelligent interactions that would help the stakeholders take appropriate decisions on various disaster-resistant practices.

Keywords: Construction guidelines, cognitive vulnerability, earthquake-resistant masonary, seismic safety.

EVALUATION of human response to risks is one of the essential pre-requisites required in the design and implementation of systems for mitigating the impact resulting from natural hazards. Several engineering interventions are proposed and adopted all over the world to reduce the seismic vulnerability of masonry structures. However, hazard occurrence and the corresponding risk interpretation, which are considered significant for effective implementation of guidelines for earthquake-resistant masonry construction, are seldom evaluated extensively. The Indian subcontinent continues to experience earthquakes of varying magnitudes, and an increased frequency of such occurrences in the future is also expected ${ }^{1,2}$. Further, India has experienced number of high-magnitude earthquakes (Richter scale 8 and above), and available reports suggest that moderate earthquakes are found to be more effective for better preparedness. Thus, it is observed that a general complacency of earthquake preparedness exists across the country due to the very low occurrence of moderate earthquakes (Richter scale 6-8) ${ }^{3}$.

*For correspondence. (e-mail: ppsivan@gectcr.ac.in)
In India, specific guidelines on earthquake-resistant construction and design of masonry are made available through the Bureau of Indian Standard publications (IS 1893 (Part 1)-2016, IS 13828-1993, IS 4326-1993, IS 1905-1987). It is prudent to undertake an evaluation of seismic-resistant features adopted in the existing buildings that have been constructed both prior and after an earthquake at a few selected vulnerable zones across the country. Ambiguity or uncertainty in the suggested solutions often forces people to rely on subject domain experts, government agencies, or fellow community members to address their inherent fear and operational constrains ${ }^{4}$. Often such systems are ill-equipped to address various misconceptions as well as to convince the local population on the need for several structural guidelines. A framework to eliminate the prevailing cognitive gaps in the adoption of earthquake-resistant masonry construction would help alleviate the aforementioned public fear, besides significantly reducing maladaptive approaches prevalent in regions with high probability for seismic exposure ${ }^{5}$. Thus, the objective of this study is to assess the extent of cognitive vulnerability at the field level based on the observed gaps and deficiencies in the implementation of earthquake-resistant masonry construction of small residential buildings, which would provide an opportunity for exploring better integration of technology-assisted systems for a detailed structural evaluation of any proposed building unit.

The aforementioned aspects are authentically assessed based on the detailed evaluation of field-level practices at two selected regions, Theekoy and Varavoor, in Kerala, South India, which also has had prior exposure to earthquakes $^{6}$. The variables considered in the analysis of cognitive factors relating to the implementation of earthquake-resistant masonry buildings are grouped into three categories: (i) collection of input factors or work domain analysis based on the evaluation of building plan geometry, mass irregularity, re-entrant corners, presence of any falling objects, wall slenderness ratio, position of wall openings and seismic bands; (ii) process evaluation or control task (or activity) analysis based on the evaluation of anticipated structural mechanisms and systems incorporated for earthquake safety - adequate structural wall density and reduced torsional eccentricity, and (iii) output factors represented by observed building response to earthquake forces based on visual inspection and responses given by the occupants ${ }^{7}$.

Figure 1 presents a detailed assessment of the present state of the buildings based on observations made during a field study. Exposure to earthquakes has certainly made both the local population and construction groups realize the requirement for incorporation of seismic bands, effective connections between walls and diaphragms, elimination of plan and mass irregularities, and reduction in re-entrant corners. Though better incorporation of seismicresistant features is observed across different timescales, 
the inconsistency in design and implementation of essential features like plinth band, sill band, lintel band and roof band exposes the cognitive conflict that exists among stakeholders at the field-level workgroup consisting of engineers, planners, supervisors and masons. Correlating observed damages in the buildings after an earthquake with the deficiencies identified in these structures based on IS code requirements, exposed the cognitive vulnerability of the aforementioned field-level workgroup in the implementation of earthquake-resistant

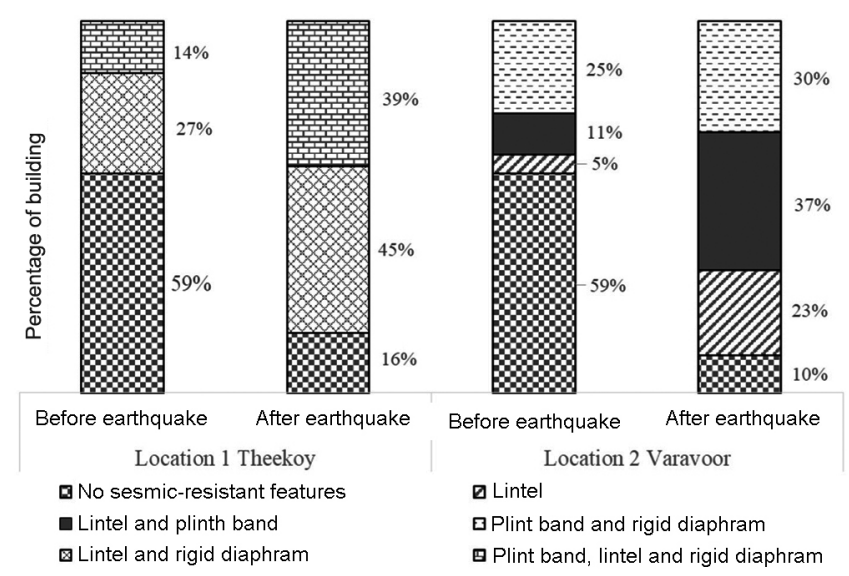

Figure 1. Incorporation of seismic-resistant features in buildings across different earthquake periods.

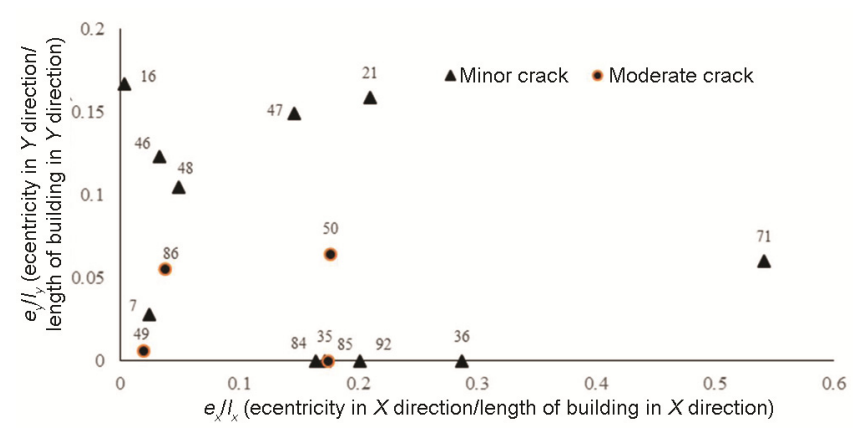

Figure 2. Torsional eccentricity and observed crack pattern in buildings (numbers indicating building reference).

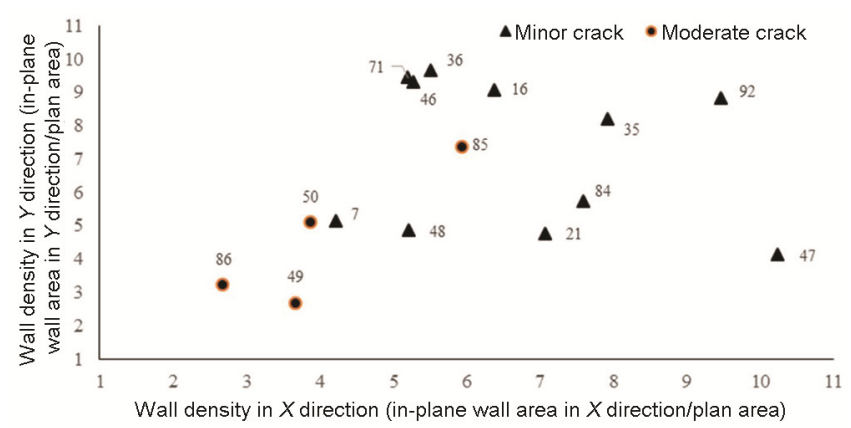

Figure 3. Structural wall density and observed crack pattern in buildings (numbers indicating building reference). masonry practices. In Figures 2 and 3, only 15 buildings whose damages were identified, among 197 buildings considered in the field study are represented. Both the figures reveal that though several geometric requirements in the buildings for seismic safety have been incorporated, the combined effect of structural wall density and torsional eccentricity ratio on buildings is not addressed in the design ${ }^{8}$. The buildings with lower eccentricity are observed to have suffered considerable damage due to their lower structural wall density (Figure 3 ). This lacuna in understanding structural responses from building configuration has resulted in cracks due to high torsional moment and corresponding excessive shear/flexural stresses during the seismic action. Further, in all the above buildings, the presence of mass irregularity along with its height also resulted in differential mass distribution in the structure causing unexpected deformation in the structural unit.

The safety suggestions, in the form of information, to mitigate the risk from natural hazards like earthquakes, need to ensure the ability of the stakeholders to understand the inherent safety level of the planned system and the preventive measures embedded in it $^{9}$. The research results have shown that though the local population is aware of the risk, the building delivery systems have not given adequate importance both to the inherent seismic hazard in these regions and the building response that could emerge from incorrect adoption of guidelines. The study has established the need for evolving effective instruments/framework, which could reduce the cognitive vulnerability in the construction of earthquake-resistant building systems. With the support of advancement in information technology systems, data availability and predictive models on building systems, the stakeholders could improve their understanding of the seismicresistant design of buildings and help respond better during earthquakes.

The observations made in this study provide clear evidence on the need for cognitive intervention to ensure better acceptability of earthquake-resistant features in masonry construction. Detailed evaluation of prevailing field-level practices in the seismically affected regions of Kerala has brought to light the existing gaps and deficiencies in the adoption of earthquake-resistant masonry construction. Though the local community is well aware of the importance of seismically safe masonry construction, the need for systems and processes to review and strengthen the cognition of the delivery group is realized from the observed engineering pitfalls. The results of this study have established the need to evolve appropriate instruments for improving the cognitive interpretation of engineering information towards better incorporation of seismic-resistant construction methods.

1. Bilham, R. and Hough, S., Future earthquakes in the Indian subcontinent: inevitable hazard, preventive risk. South Asian J., 2006, 12. 
2. Jain, S. K. and Nigam, N. C., Historical developments and current status of earthquake engineering in India. 12th World Congress on Earthquake Engineering, Auckland, New Zealand, 2000.

3. Jain, S. K., Indian earthquakes - an overview. Indian Concr. J., 1998, 72, 555-561.

4. Pinchao, L., Liuxin, J., Bingsheng, L., Changtao, C., Dongping, F., Peilun, R. and Mengchun, Z., A cognitive perspective on the safety communication factors that affect worker behavior. J. Build. Constr. Plann. Res., 2014, 2, 183-197.

5. Vicente, K. J., Cognitive Work Analysis, Lawrence Erlbaum Associates, Mahwah, New Jersey, London, 1999.

6. Rajendran, C. P., John, B., Sreekumari, K. and Rajendran, K., Reassessing earthquake hazard in Kerala based on the historical and current seismicity. J. Geol. Soc. India, 2009, 73, 785-802.

7. McClure, J., White, J. and Sibley, C. G., Framing effects on preparation intentions: distinguishing actions and outcomes. Disaster Prevent. Manage., 2009, 18, 187-199.

8. Tena-Colunga, A. and López-Blancas, A., Allowable torsional eccentricity for the simplified method for the seismic analysis of low-rise confined masonry shear - wall buildings of Mexican Codes. Open Civ. Eng. J., 2011, 5, 132-142.

9. Eiser. J. R. et al., Risk interpretation and action: a conceptual framework for responses to natural hazards. Int. J. Disaster Risk Reduction, 2012, 1, 5-16.

\section{Performance of sorghum genotypes under zero tillage conditions in rice fallows with reference to stem borer Chilo partellus}

\author{
P. Yogeswari ${ }^{1}$, C. Sandhya $\operatorname{Rani}^{1, *}$ and \\ G. Ramachandra Rao ${ }^{2}$ \\ ${ }^{1}$ Department of Entomology, Agricultural College, \\ Bapatla 522 103, India \\ ${ }^{2}$ Department of Environmental Science, \\ Advanced Post Graduate Centre, Lam, Guntur 522 034, India
}

A field experiment was carried out to screen the sorghum genotypes against stem borer in rice fallow under zero tillage condition. Based on mean stem tunnel length, the genotypes were categorized as least susceptible $(0-5 \mathrm{~cm})$, moderately susceptible $(5-10 \mathrm{~cm})$ and highly susceptible $(>10 \mathrm{~cm})$. The resistant check CSH 16 (C) was found least susceptible with $4.65 \mathrm{~cm}$, whereas NTJ-2 (C), NLCW-6 and N-14 were found to be highly susceptible as they recorded $10.45,10.46$ and $11.44 \mathrm{~cm}$ mean stem tunnel length respectively. The

\footnotetext{
*For correspondence. (e-mail: gajularamatha@gmail.com)
}

remaining genotypes were moderately susceptible with $6.60-9.84 \mathrm{~cm}$ mean stem tunnel length. There was non-significant positive correlation between the number of larvae and leaf damage, dead hearts, stem tunnelling, white ears and chaffy grains respectively, but it was negative for tiller damage.

Keywords: Genotypes, sorghum, stem borer, stem tunnel length, susceptible.

SoRGHUM [Sorghum bicolor (L.) Moench] is the fifth major cereal crop after wheat, rice, maize and barley. It is the most important crop of Asia, Africa, Australia, America and is cultivated as a staple crop in the semi-arid tropics (SAT). In India, it is cultivated in an area of $6.18 \mathrm{~m}$ ha with 5.33 million tonnes $(\mathrm{mt})$ production and productivity of $863 \mathrm{~kg} /$ ha (ref. 1). In general sorghum is cultivated during kharif, maghi (late kharif) and rabi seasons in Andhra Pradesh (AP) in an area of 287,000 ha with production of 546,000 tonne and productivity of $1904 \mathrm{~kg} / \mathrm{ha}$ (ref. 2) as against normal area of 760,000 ha with production of 552,000 tonne and productivity of $730 \mathrm{~kg} / \mathrm{ha}$. The reasons for low productivity under normal type of cultivation might be due to shifting of jowar area to cultivation of commercial crops, high humidity in the coastal regions, and ravage due to pests and diseases in jowar-cultivating areas.

Insect pest conditions are dynamic in nature and change with climate and farming practices - introduction of improved varieties has been known to result in pest outbreaks or changes in pest status ${ }^{3}$. Sorghum is attacked by more than 150 insect species causing $32 \%$ crop loss ${ }^{4}$. Losses in sorghum due to insect pests differ on a regional basis and have been estimated at US\$ 1089 million in the SAT, US\$ 250 million in USA and US\$ 80 million in Australia ${ }^{5}$. Among the insect pests, shoot fly, Atherigona soccata (Rondani) and stem borer, Chilo partellus (Swinhoe) are the major threats causing $75.6 \%$ and $24.3-36.3 \%$ yield loss respectively ${ }^{6}$.

Management of the pests is being done using pesticides. However, due to the adverse effects of pesticides, it is imperative to seek for alternate integrated pest management methods like host plant resistance, which it not only cost-effective and does not require application skills in pest control techniques, but also enhances the effectiveness of natural enemies and reduces the need to use pesticides $^{7}$. The effect of resistant genotypes on insect population is continuous and cumulative over time. Umakanth et al. ${ }^{8}$ reported 'SPV 1022', 'PKV809' and 'CO28' as promising sorghum cultivars in rice fallows.

Performance of sorghum genotypes under zero tillage conditions in rice fallows with reference to stem borer was carried out during rabi 2014-15 in the southern block of Agricultural College Farm, Bapatla, Guntur district, AP. Studies were carried out to screen the sorghum genotypes against shoot fly in rice fallow under zero 